\title{
Analysis of Latin American Literature through a Mathematical Lens
}

\author{
Hugo Romeo Cedeño Cedeño \\ Purdue University Northwest, United Stade \\ Corresponding author email: hcedenoc@purdue.edu \\ Telly Yarita Macías Zambrano \\ Instituto Superior Tecnológico Paulo Emilio Macías, Portoviejo, Manabí, Ecuador
}

\begin{abstract}
Several of the most influential Latin American writers were interested in the sciences. Moreover, a handful showed an affinity to mathematics since childhood, eventually following careers as physicists, engineers, and mathematicians before turning their attention to the arts. In the end, they became novelists, essayists, and poets, who made significant contributions to their field. There is a large amount of existent traditional literature analysis research on Latin American authors. In the last sixteen years, research has shifted to include a focus on the connection between math and literature. However, this research focuses on interpreting the ideas of the universally acclaimed writer Jorge Luis Borges, studying his scientific thinking through his works, and demonstrating the writings included both basic and advanced math concepts even though he lacked a formal mathematical and scientific formation. Currently, there is a gap in the research that ignores the influential Latin American authors who were also prolific in mathematics. As a math and engineering student, I am interested in studying the work of Latin American writers with academic backgrounds in STEM fields--specifically mathematics. I intend to examine the writings of Ernesto Sabato, Guillermo Martinez, and Nicanor Parra for explicit math terminology and concepts. I will analyze the content of these writings and any references to popular mathematical theories during the time in which these authors were active. I am curious to find out if their strong background and understanding of mathematics influenced their literature.

Keywords---Latin American, literature, mathematical lens.
\end{abstract}

\section{Introduction}

The 20th century was a prolific period for literature in Latin America. To mention a handful of distinguished writers, one should mention Nobel Prize laureates such as Gabriela Mistral, Miguel Angel Asturias, Pablo Neruda, Octavio Paz, Gabriel García Márquez and Mario Vargas Llosa. We also have the short stories of Jorge Luis Borges, Mario Benedetti, Julio Cortázar and Horacio Quiroga; the novels of Carlos Fuentes, Isabel Allende and José Donoso. These authors and many others had a strong influence not only in Latin America but worldwide, their works left a significant imprint in other literary works and their legacy echoes all way up to the present time.

The origins of the so-called Latin American "boom" can be found in Paris right after the end of World War I, when many young artists and writers came back home from the Western front with a new mindset, their ideas developed into the surrealist movement during the early 1920s. Paris attracted many young Latin American writers that were visiting Europe, interested in opportunities to exchange ideas and find inspiration for their works. In time, they brought the surrealistic manifesto to the Americas and helped to make it popular (Borges, 1941; Martínez, 2006; Parra, 1937; Sábato, 1951). A notable example is Borges who in his youth went to study at Geneva and took frequent visits to Paris where he got in contact with some of the very first surrealistic writers, Borges adopted many of their ideas into his work, and later on, he became one of the founders of literature of the fantastic. Neruda, who was one of the most influential authors of his time, also embraced the ideas of surrealism and helped to spread them, causing a domino effect that propagated this literary style through decades.

Besides realism surrealism, the fantastic and magical realism, starting with Borges, the influence of sciences in the literature is noticeable. Although at the beginning is not frequent to find such influence, by the end of the century 
the reference and discussion of different STEM-related topics became more popular among writers, especially novelists (Martínez, 2013; Parra, 1954; Martínez, 2007; Sábato, 2004). This trend continues in the 21st, and today many STEM subjects are popular topics of discussion in novels, essays, and short stories of Latin American authors. Most of the time, the discussions cover STEM subjects briefly and they are not fundamental in the structure or argument of a literary work. The influence of sciences is a clear indication of the interest that fiction writers had in them. Where their interest in science came from can be found by researching their biographies and analyzing their writings.

\section{The math-literature connection}

Recent research in Latin American literature has shifted to include a focus on the connection between math and literature. The reason behind this is the fact that mathematics is the basis for exact sciences, therefore proving the existence of a connection or affinity of writers with math is a way to ultimately determine the extent of the influence that exact sciences have in literature (Martínez, 2019; Parra \& Ortega, 1994; Sábato, 1945). Many of Borges' publications introduce the reader to both basic and advanced mathematical concepts. In the last sixteen years, there has been a lot of research about the interest of Borges in math and its influence on his writings. Although Borges lacked a formal mathematical and scientific formation, his explicit interest in math shows his sincere fascination and affinity with numbers.

Borges used math extensively in many of his works, being in some cases fundamental to the structure of his novels and short stories. Among mathematicians worldwide, the short stories "The Aleph" (1945) and the "Library of Babel" (1941) are well known. "The Aleph" is a direct reference to the aleph numbers, which are sequences of numbers that represent the cardinality of well-ordered infinite sets (Borges, 1945). An example of an aleph number is the cardinality of the set of natural numbers. George Cantor, a German mathematician and founder of the set theory, defined aleph numbers. On page 285 of this story, Borges mentions, "For the Mengenlehre, the aleph is the symbol of the transfinite numbers, in which the whole is not greater than any of the parts". The word "Mengenlehre" is the German name for "set theory". Another mathematical concept discussed in "The Aleph" is the infinity of the continuum, which also derives from set theory, being the cardinality of the real numbers. Cantor was active during the late 19th and early 20th centuries, some of his work and Borges while studying and living in Europe must have read some of his works and publications.

In "The Library of Babel". Borges alludes to Euclidean geometry and talks about paradoxes. The fantastic library itself is a paradox, theorized by Borges to be infinite in size and being made by an uncountable number of hexagonal rooms connected with a staircase. Permutations, analytical series, and set theory are all integrated into this story. The vivid description of the library provides the following information:

1) Each hexagonal room contains 20 shelves of books.

2) Each shelf contains 32 books and each book is exactly 410 pages long.

3) Each page contains exactly 40 lines and each line contains exactly 80 characters.

4) The characters consist of 22 letters, all lower case, the period, the comma, and space; 25 in total.

It seems that Borges intended the library to be a math riddle, using the information provided above one can determine after some calculations that the stack of all the papers in the library has a height that is 93 billion times the size of the known universe, while the stack of books is a 1834070 digits long number. Borges also wrote a murder mystery story, "The death and the compass" (1942), where he uses mathematical series and geometry as the pattern of the killings. This story influenced the works of future authors like Guillermo Martínez. Borges' passion and love for math expose the reader to a wide spectrum of topics, there is no doubt that Borges teaches math through his literature

\section{Gaps in the literature}

Currently, there is no research about other influential Latin American writers that have a proven affinity with math and formal education in STEM-related areas; although among them, we find physicists, engineers, and pure mathematicians that worked in their fields for years before switching to a new career in literature, ultimately making significant contributions (Kitchenham et al., 2009; Da Silveira et al., 2001). These writers were prolific in both arts and exact sciences. While Borges only had a high school diploma, other writers had doctoral degrees in sciences; they also became novelists, essayists, and poets. The current gap in the literature is the study of their work and the 
influence that their background had on it. For this study, I examined the writings of Ernesto Sabato, Guillermo Martinez, and Nicanor Parra for explicit math terminology and concepts. I checked for any references to popular mathematical theories during the time in which these authors were active (Brereton et al., 2007; Marik et al., 2008). The objective of my work is to find out if their strong background and understanding of mathematics influenced their literature.

\section{The math and physics of Sabato}

Ernesto Sabato (1911-2011) was an Argentinian novelist, essayist, and physicist. He studied physics at Universidad de la Plata, where he got his Ph.D. degree in 1938. In the same year, he started his postdoctoral fellowship in atomic radiation at the Curie Institute in Paris. The next year he became a research fellow for MIT (Sabato, 1974; Sábato, 2000; Tait, 1986). In 1940, he returned to Argentina and got a teaching position as a professor of relativity and quantum mechanics at Universidad de la Plata. In his autobiography "Before the end" (1998), talks about the influence that surrealism had on him, exposed to it during his time in Paris. He states that: "At the Curie Institute, one of the highest goals for a physicist, I found myself empty. Beaten up by disbelief, I kept going because of inertia, which my soul rejected. During that time of antagonisms, I buried myself with electrometers and graduated cylinders during the morning and spent the nights in bars, with the delirious surrealists."

The exposure to the ideas of surrealists was the catalysts of his shift to the arts, although he continued teaching physics until 1943. As a writer, he was very prolific, winning many different awards and receiving recognition for his work through the rest of his life. Sabato won the best foreign novel Prize (France, 1975), the Medici Prize to the best foreign book (Italy, 1977), the Miguel de Cervantes Prize (Spain, 1984), and many more.

From all his works, the ones I use for this study are:

1) "The Tunnel", 1948.

2) “On heroes and tombs", 1961.

3) "The Angel of Darkness" 1974

4) "One and the universe", 1945.

5) "Man, and mechanism",1951.

6) "Before the end", 1998.

The first three are his most famous novels; the other two are essays and the last one the autobiography already mentioned. I read these works and searched for mathematical concepts. In the novels and the autobiography, there is no reference of any specific math concept, neither a discussion of a topic in math (Boyce et al., 2002; Frost, 2010; Parks, 2008; Mahendra, 2016). In "Man and mechanism", there are discussions between a page and a paragraph about Newton's gravitational law, Einstein's theory of relativity, and logarithms. However, is in "One and the universe: that the full knowledge and interest of Sabato in the exact sciences are found, some of the findings are listed below:

1) Page 10: He talks about mathematical logic, the Pythagoras' theorem, and hypotenuses.

2) Page 12: "The entropy of an isolated system is strictly increasing". Here he describes the behavior of a system's entropy.

3) Page 13: "The green of those trees that the air wags occupies an area of the spectrum around 5000 Angstrom units". He provides the wavelength of the electromagnetic spectrum that produces green color, and then he goes beyond and explains how a microphone captures the frequency of waves to create sounds. At the bottom of the page, he mentions sinusoids, logarithms, triangles, and probability waves.

4) Page 14: Sabato takes a long paragraph to briefly tell the story of how the theory of relativity changed the way we see the universe, from matter moving in space to unified time-space events. He mentions that matter is an expression of time-space curvature and that some relativists imagine a timeless universe.

5) Page 16: "The Alfonsine tables, astronomical data used for computing the position of the Sun, the Moon and the planets relative to fixed stars". The tables that he refers to are a collection of astronomical charts published by king Alfonso $\mathrm{X}$ of Castile during the middle ages.

6) Page 19: He mentions tensor calculus, algebraic structures, group theory, and tetra dimensional geodesics, being the latter an advanced topic in differential geometry.

7) Page 22: He talks about W. Sitter's theory of the universe's expansion and gives an explanation using the relativity theory. In the next paragraph, he talks about mechanic vibrations and how they correlate to the frequency of an electromagnetic wave. 
8) Page 23: "Einstein's first gravitational law states that the $G$ tensor is null. Einstein modified his equation to make space a closed one for long distances and give it a finite dimension". He also mentions the big bang theory.

9) Page 24: "Eddington combined the theory of relativity applied to the universe and the quantic theory applied to the atom". On the next two pages, he talks about quantum theory, its evolution and the points of view that the scientific community has about it.

10) Page 27: He mentions that the cosmic number (total number of particles contained in the universe) is $2136.2^{\wedge}$ $256 "$.

After this, "One and the universe" talks about history and culture, it becomes more philosophical and discusses the ethics of science. This essay proves Sabato's strong background, interest, and affinity with both math and physics. Published in 1945, the essay mentions and discusses many theories that were popular during the first half of the 20th century, in the context of math and physics. Regarding math, there are mentions of advanced topics like tensor calculus, algebraic structures, and group theory. At the time, group theory was a very popular topic and that is why Borges also uses it for "The Aleph".

\section{Nicanor Parra and the creation of antipoems}

Parra was a very influential poet from Chile, but he also worked as a mathematician and physicist. Born in 1914, his trajectory of almost a century was very prolific, dying just recently in 2018 . He got a bachelor's degree in Mathematics and Physics from Universidad de Chile in 1937, in the same year he published his first book "Songbook without a name". From 1943 to 1947, he studied physics and advanced mechanics at Brown University. Afterward, he studied cosmology at Oxford University between 1949 and 1951. In 1952, he became a professor of theoretical physics at Universidad de Chile (Bengoa \& Sanchez-Robles, 2003; Menezes et al., 2005). During the 50's he was teaching at Columbia, Yale, New York University, and Louisiana State University. He published his second book "Poems and antipoems" in 1954, antipoems are poems with fewer verses and more prose, Parra was the first antipoet. For many decades until retiring in the 1990s, Parra was a physics teacher, but he continued to write literature until the year before his death. His work and legacy in Chile are significant; many people compare him with Neruda as an outstanding poet (Yeyati \& Micco,2007; Giuliani et al., 2005). He was nominated four times for the Nobel Prize in Literature, although he never won one, he received the "Reina Sofía" Prize (Spain, 2001), the Miguel de Cervantes Prize (Spain, 2011), and the Pablo Neruda Ibero-American poetry award (Chile, 2012). For this study, I selected his most important works, collections of poems and antipoems published between 1937 and 1993. These works are:

1) Songbook without a Name", 1937.

2) "Poems and Antipoems", 1954.

3) "The Anti-Lazarus", 1981.

4) "Poems to Combat Baldness", 1993

After reading them exhaustively, I could not find any reference to a mathematical concept or topic. Since these are the most representative of his works, it seems that although he had extensive formation and studies in math, it did not influence his works significantly. Parra's antipoems focus on nature, human life, Chilean politics, and topics related to humanities.

\section{From Borges to Martínez}

Guillermo Martínez is an Argentinian writer born in 1962. In 1992, he obtained his Ph.D. in Mathematical Logic from the University of Buenos Aires. From 1993 to 1995, he was a postdoctoral fellow at Oxford University, this period and his experiences while in Oxford were fundamental for his future works. Martínez writes novels and short stories, his style is a reminiscence of Borges's writings all his novels discuss math topics and most of them focus heavily on math. He won the Mandarache Prize (Spain, 2006), the Gabriel García Márquez Prize (Colombia, 2014), and the Nadal Prize for best novel (Spain, 2019).

For this study, I selected the following publications of Martínez:

1) "Borges and Mathematics", 2003.

2) "The Oxford Murders", 2003. 
3) "The Book of Murder", 2007.

4) "Alicia's crimes", 2019.

The first one is a book that analyses the mathematical content in Borges' literary work and the passion for math that he had during his lifetime. Martínez research on Borges is one of the first serious studies about the connection between math and literature. As expected from the title and topic, this book is based on the math within the literature of Borges, discussing the rich mathematical content of "The Aleph", "The Library of Babel" and other works. "Borges and Mathematics" is proof of Martinez's mastery of math since he easily and clearly explains the favorite math topic Borges, explaining Borges' reasons and motivations. Martinez is also a big admirer of Borges, the murder mystery novel "The death and the compass" had a lasting influence on him, since he found in this book his love for mathematical murder mysteries, and in the same style, he wrote three novels of his own.

"The Oxford Murders" is probably Martinez's best work. A critically acclaimed bestseller worldwide, this murder mystery novel follows the story of a logic professor assisted by his graduate student in the investigation of math-based murders. In the novel, the killer has strong knowledge in advanced math topics, carefully planning the murder of his victims and leaving at every crime scene a hint related to a mathematical shape that obeys a sequence. The hint is always a symbol that represents a unique geometry. The killing patterns and the time between each death also follow the behavior of a sequence, an absolute convergent sequence to be more specific. During their time together, the main characters work endlessly in trying to solve the case, finding out during the investigation that to stop the serial killer they need to decode the sequence of the shapes left behind and predict the next symbol in the sequence. After failing in decoding the sequence for several days, the professor and his student find a way to solve the encrypted code of the new clues and identify the sequence pattern, which leads to them solving the case. There is a movie (released in 2008) based on the book, directed by Alex de la Iglesia; also starred Elijah Wood, John Hurt, Leonor Watling, and Julie Cox.

Out of all the math topics in the novel, the one that appealed to me the most was Wittgenstein's rule-following paradox, which states: "No course of action could be determined by a rule because any course of action can be made out to accord with the rule". Originally, Saul Kripke established this paradox in 1982 (a philosopher of languages) but it has an analogy that can be found in mathematics and explained the following way:

1) Assume that you have ever performed the addition of two numbers greater than 20.

2) Suppose that somebody asks you to calculate $28+32$.

3) Logically you are expected to calculate the answer using the rules of addition, as you know them, operating $28+32=60$.

4) However, somebody can say that this is not true since previous knowledge of different addition operations (with numbers smaller than 20) does not justify the answer that you are getting.

5) There is nothing that confirms or proves your solution, the answer could be 8 and you have no way to prove it wrong.

6) You are susceptible to infinite interpretations and solutions for the problem.

7) If you want to find the rules of addition for numbers greater than 20 without previous knowledge, then you have infinite interpretations of the rules.

8) Therefore, conclude that interpretations by themselves do not determine to mean.

Another notable topic in "The Oxford Murders" is the principle of uncertainty, which says that "the more precisely the position of some particle is determined, the less precisely its momentum can be known". The novel discusses Gödel's Theorem, a theorem of logical mathematics for axiomatic systems. The year that Martínez arrived at Oxford, British mathematician Andres Wiles proved Fermat's Last Theorem. An alumnus from Oxford, Wiles developed a proof that had avoided mathematicians for more than three hundred years. The publication of the proof is one of the main events in the novel, although instead of Wiles a fictional character was the one who found the solution. Fermat's last theorem says that the equation $\mathrm{xn}+\mathrm{yn}=\mathrm{zn}$ has no solutions in integers for values of $\mathrm{n} \geq 3$.

"The Book of Murder" and "Alicia's crimes" are other two mathematical murder mysteries. While the first one follows the same formula as "The Oxford Murders", the second one adds a little more fiction. "Alicia's crimes" has been in stores since just two months ago, and although very new, it has already good reviews. The argument is about the missing pages in Lewis Carroll's diary (the author of Alice in Wonderland), with references to Carrol and his most famous novel. "Alicia's crimes" focus deeply on mathematical series. It discusses topics in calculus, combination theory, statistics, and group theory.) 


\section{Conclusions}

Sabato's essays show a strong background and understanding of mathematics. His essays talk about popular theories in physics and math, also discuss the intersection between philosophy, mathematics, and physics; but his novels lack any mention or discussion of relevant mathematical theories or concepts. After reading some selected works of Sabato, it is evident that he progressively abandoned the use of math in his works since "One and the universe" and "Man and mechanism" were published just a few years after he abandoned his career in academia. "One and the universe" was his first work. The mathematical background that he had influenced his early works only. Parra had an extensive formation in advanced mathematics and physics, but nothing relevant was found in his poems. Mathematics did not influence his writings. Martinez is up to date in popular mathematical topics and theories. He is very prolific in both math and literature. For the case of Martinez, is evident that mathematics has a strong influence on his work since he wrote three murder mystery novels. Today he is viewed as the most important mathematical murder mystery author.

\section{References}

Bengoa, M., \& Sanchez-Robles, B. (2003). Foreign direct investment, economic freedom and growth: new evidence from Latin America. European journal of political economy, 19(3), 529-545. https://doi.org/10.1016/S01762680(03)00011-9

Borges, J. L. (1941). El jardin de senderos que se bifurcan. Buenos Aires: Sur. Translated by DA Yates (1964). Labyrinths: Selected Stories \& Other Writings, 19-29.

Borges, J.L. (1945). El Aleph. Buenos Aires: Editorial Sur.

Boyce, J. F., Bhermi, G. S., Spalton, D. J., \& El-Osta, A. R. (2002). Mathematical modeling of the forces between an intraocular lens and the capsule. Journal of Cataract \& Refractive Surgery, 28(10), 1853-1859. https://doi.org/10.1016/S0886-3350(02)01490-6

Brereton, P., Kitchenham, B. A., Budgen, D., Turner, M., \& Khalil, M. (2007). Lessons from applying the systematic literature review process within the software engineering domain. Journal of systems and software, 80(4), 571583. https://doi.org/10.1016/j.jss.2006.07.009

Da Silveira, G., Borenstein, D., \& Fogliatto, F. S. (2001). Mass customization: Literature review and research directions. International journal of production economics, 72(1), 1-13. https://doi.org/10.1016/S09255273(00)00079-7

Frost, J. H. (2010). Looking through the lens of a teacher's life: The power of prototypical stories in understanding teachers' instructional decisions in mathematics. Teaching and teacher education, 26(2), 225-233. https://doi.org/10.1016/j.tate.2009.03.020

Giuliani, E., Pietrobelli, C., \& Rabellotti, R. (2005). Upgrading in global value chains: lessons from Latin American clusters. World development, 33(4), 549-573. https://doi.org/10.1016/j.worlddev.2005.01.002

Kitchenham, B., Brereton, O. P., Budgen, D., Turner, M., Bailey, J., \& Linkman, S. (2009). Systematic literature reviews in software engineering-a systematic literature review. Information and software technology, 51(1), 715. https://doi.org/10.1016/j.infsof.2008.09.009

Mahendra, I. (2016). Contextual learning approach and performance assessment in mathematics learning. International Research Journal of Management, IT \& Social Sciences, 3(3), 7-15.

Marik, P. E., Baram, M., \& Vahid, B. (2008). Does central venous pressure predict fluid responsiveness?*: A systematic review of the literature and the tale of seven mares. Chest, 134(1), 172-178. https://doi.org/10.1378/chest.07-2331

Martínez, G. (2006). Borges and mathematics.

Martínez, G. (2007). Slow death of Luciana B . Destino Editions.

Martínez, G. (2013). Crímenes imperceptibles. Planeta.

Martínez, G. (2019). Alicia's crimes. Buenos Aires: Destination .

Menezes, A. M. B., Perez-Padilla, R., Jardim, J. B., Muiño, A., Lopez, M. V., Valdivia, G., ... \& PLATINO Team. (2005). Chronic obstructive pulmonary disease in five Latin American cities (the PLATINO study): a prevalence study. The Lancet, 366(9500), 1875-1881. https://doi.org/10.1016/S0140-6736(05)67632-5

Parks, A. N. (2008). Messy learning: Preservice teachers' lesson-study conversations about mathematics and students. Teaching and Teacher Education, 24(5), 1200-1216. https://doi.org/10.1016/j.tate.2007.04.003

Parra, N. (1937). Cancionero sin nombre. Nascimento.

Parra, N. (1954). Poems and antipoems . University Publishing House. 
Parra, N., \& Ortega, J. (1994). Poemas para combatir la calvicie. Fondo de cultura económica.

Sabato, E. (1974). Abbadón el exterminador. Buenos Aires: Editorial Sudamericana.

Sábato, E. (2000). Before the end: memories. Seix Barral, 1998.

Sábato, E. (2004). On heroes and graves (Vol. 117). Ayacuch Library Foundation.

Sábato, ER (1945). One and the universe . Editorial Sudamericana.

Sábato, ER (1951). Men and Gears: Reflections on Money, Reason, and the Collapse of Our Time. Emecé editors.

Tait, W. (1986). Wittgenstein and the "Skeptical Paradoxes," reprinted in (William Tait) The provenance of pure reason, 198-211 (2005).

Yeyati, E. L., \& Micco, A. (2007). Concentration and foreign penetration in Latin American banking sectors: Impact on competition and risk. Journal of Banking \& Finance, 31(6), 1633-1647. https://doi.org/10.1016/j.jbankfin.2006.11.003 